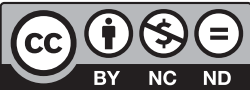

Estudos Teológicos foi licenciado com uma Licença Creative Commons Atribuição - NãoComercial - SemDerivados 3.0 Não Adaptada

http://dx.doi.org/10.22351/et.v60i1.3468

\title{
Teoria do Apego e apego a Deus no aconselhamento: ESTUDO DE CASO ${ }^{1}$ \\ Attachment Theory and Attachment to God in Counseling: A Case Study
}

\section{Hartmut August ${ }^{2}$ Mary Rute G. Esperandio ${ }^{3}$}

Resumo: Poucos estudos aplicam os conceitos da Teoria do Apego e do apego a Deus no aconselhamento. Os sentimentos de ligação e dependência que se criam entre criança e a pessoa que faz o cuidado moldam os estilos e a maneira como ela irá se relacionar nas fases seguintes da vida. O relacionamento com Deus também é uma relação de apego. $\mathrm{O}$ propósito deste artigo consiste em demonstrar a aplicação da Teoria do Apego a Deus no processo de aconselhamento espiritual. Discute-se a prática do cuidado espiritual como caminho para a transformação dos modelos internos de funcionamento do apego. Adotou-se a metodologia de estudo de caso individual instrumental. Foram realizados sete encontros com uma jovem de 28 anos em busca de orientação para suas inseguranças no namoro. $\mathrm{O}$ processo de aconselhamento possibilitou o desenvolvimento de um relacionamento mais próximo com Deus, ampliação da segurança da base interna, maior segurança no relacionamento amoroso e diminuição gradativa da ansiedade. Aplicando os conceitos do apego, o aconselhamento proporciona um ambiente seguro, onde as experiências e emoções do passado são trabalhadas numa aliança conselheiro ou conselheira e aconselhando ou aconselhanda e permite ampliar a segurança com Deus, consigo ou com outros, indicando que tais conceitos podem ser aplicados com êxito no contexto de um aconselhamento no qual as partes pressupõem a existência de Deus como Ser relacional.

Palavras-chave: Teoria do Apego. Apego a Deus. Aconselhamento espiritual.

Abstract: Few studies apply the concepts of the Attachment Theory and Attachment to God in counseling. The feelings of attachment and dependency that are created between child and caregiver shape the styles and the way in which the person will relate to others in the later stages of life. The relationship with God is also an attachment relationship. The purpose of this article is to demonstrate the application of the Attachment to God theory in the spiritual counseling process. The practice of spiritual care is discussed as a way to transform the internal working models of attachment. The methodology of

1 O artigo foi recebido em 22 de maio de 2019 e aprovado em 15 de junho de 2020 com base nas avaliações dos pareceristas ad hoc.

2 Doutor em Teologia. Faculdade Fidelis. E-mail: hartmut.august@fidelis.edu.br

3 Doutora em Teologia. PUCPR. E-mail: mary.esperandio@pucpr.br 
individual instrumental case study was adopted. Seven meetings were held with a 28 years old woman in search of guidance on her insecurities in her loving relationship. The counseling process enabled the development of a closer relationship with God, an increase in her inner base of security, greater security in her loving relationship, and a gradual decrease of anxiety. Applying the concepts of attachment, the counseling process provides a secure environment in which the experiences and emotions of the past are worked out in a counselor-patient alliance, and it allows to increase security with God, with oneself or with others, indicating that such concepts can be successfully applied in the context of counseling, where the parties presuppose the existence of God as a relational Being.

Keywords: Attachment to God. Attachment Theory. Spiritual Counseling.

\section{Introdução}

O propósito deste artigo consiste em descrever um estudo de caso no qual a Teoria do Apego e o apego a Deus foram aplicadas na prática do aconselhamento espiritual.

A Teoria do Apego foi inicialmente estruturada pelo psicanalista britânico John Bowlby (1907-1990). Ao pesquisar o comportamento humano, em especial o relacionamento das crianças com seus pais, Bowlby propôs que o elemento mais relevante na relação entre a criança e seus pais é o vínculo que se estabelece entre eles desde a mais tenra idade.

Os psicólogos da religião Kirkpatrick e Shaver propuseram que o apego também se constitui num aspecto relevante no campo das crenças e práticas religiosas, sugerindo que a relação com Deus também pode ser considerada uma relação de apego. ${ }^{4}$ A partir desses estudos pioneiros, outros trabalhos prosseguiram na direção de compreender o relacionamento da pessoa com Deus como sendo uma relação de apego. ${ }^{5}$

Na perspectiva da teologia cristã, Deus é um ser relacional e de amor. ${ }^{6}$ Ao criar o ser humano à sua imagem e semelhança ${ }^{7}$, Deus o torna também um ser relacional ${ }^{8}$ e o capacita a desenvolver relacionamentos seguros (inclusive relações de apego) e a amar. Porém, como consequência da queda em pecado, a tomada de consciência de

4 KIRKPATRICK, Lee A.; SHAVER, Phillip R. Attachment Theory and Religion: Childhood Attachments, Religious Beliefs, and Conversion. Journal for the Scientific Study of Religion, v. 29, n. 3, p. 315, Set. 1990. KIRKPATRICK, Lee A.; SHAVER, Phillip R. An attachment-theoretical approach of romantic love and religious belief. Personality and Social Psychology Bulletin, v. 18, p. 266-275, 1992.

5 Por exemplo, KIRKPATRICK, Lee A. Attachment, Evolution, and the Psychology of Religion. New York: Guilford, 2005. GRANQVIST, Pehr; MIKULINCER, Mario; SHAVER, Phillip R. Religion as attachment: normative processes and individual differences. Pers Soc Psychol Rev., 14(1), p. 49-59, Feb. 2010. Review. GRANQVIST, Pehr; KIRKPATRICK, Lee A. Attachment and Religious Representations and Behavior. In: Handbook of Attachment: Theory, Research, and Clinical Applications. 2. ed. New York: Guilford, 2008. p. 906-933.

6 SOUZA, Ricardo Barbosa de. O Caminho do Coração. 4. ed. Curitiba: Encontro, 2002. p. 59.

7 Então disse Deus: "Façamos os seres humanos à nossa imagem, de forma que reflitam a nossa natureza" (Gênesis 1.26a). BÍBLIA A Mensagem: Bíblia em Linguagem Contemporânea. São Paulo: Vida, 2011.

8 MINER, Maureen. Back to the basics in attachment to God: revisiting theory in light of theology. Journal of Psychology and Theology, Cengage Learning, Inc., v. 35(2), p. 112-123, Summer 2007. p. 116. 
sua finitude gera angústia no ser humano. ${ }^{9}$ Contudo, mediante um relacionamento de confiança e dependência de Deus (apego seguro a Deus), o ser humano pode superar as angústias da vida. ${ }^{10} \mathrm{Um}$ "apego seguro com Deus pode contribuir para uma base segura interna" "11, propiciando a exploração saudável do intelecto, tolerância à frustração, autoestima, introjeção positiva, narcisismo saudável, otimismo e esperança. ${ }^{12}$ Um apego seguro com Deus também possibilita a construção ou restauração dos apegos interpessoais. ${ }^{13}$ Além disso, novas experiências podem dar significado novo às experiências anteriores, inclusive experiências de apegos inseguros.

Considerando que o aconselhamento individual tem "uma função reparadora, necessária quando o crescimento das pessoas é seriamente comprometido ou bloqueado por crises" ${ }^{14}$, o estudo de caso aqui apresentado tem por base o aconselhamento espiritual prestado a uma jovem de 28 anos que busca ajuda para suas inseguranças no namoro. No momento em que Fernanda ${ }^{15}$ busca aconselhamento, ela, seu filho de oito anos e seu companheiro estão vivendo juntos há cerca de seis meses. Os assuntos que mais a incomodam são as frequentes brigas com seu namorado e os ciúmes que ela sente na relação dele com sua ex-mulher.

De que modo a Teoria do Apego e o apego a Deus podem contribuir no aconselhamento espiritual do caso apresentado? Este estudo descreve a realização desse processo. Para isso apresenta, inicialmente, os fundamentos da Teoria do Apego e do apego a Deus, os procedimentos metodológicos empregados e discute os resultados de sua aplicação teórico-prática.

As considerações finais resumem os principais achados do estudo, visando subsidiar futuras aplicações dos conceitos do apego e do apego a Deus no aconselhamento espiritual.

\section{Fundamentos da Teoria do Apego e do apego a Deus}

John Bowlby ${ }^{16}$ produziu uma vasta literatura a partir de pesquisas empíricas, desenvolvendo o que passou a ser conhecida como Teoria do Apego (Attachment Theory). Bowlby define o comportamento de apego como "qualquer forma de comportamento que caracteriza o movimento feito por uma pessoa para obter ou reter proximidade com alguma outra, diferenciada e preferida, que geralmente é concebida como

9 TILLICH, Paul. Teologia Sistemática. São Leopoldo: Sinodal; EST, 2005. p. 200.

${ }^{10}$ TILLICH, 2005, p. 173.

11 ALLEN, Jon G. Restoring Mentalizing in Attachment Relationships. Arlington, USA: American Psychiatric, 2013. p. 234.

12 MIKULINCER, Mario; SHAVER, Philip R. Attachment in Adulthood-Structure, Dynamics, and Change. New York: Guilford, 2010. p. 153.

${ }_{13}$ ALLEN, 2013, p. 238.

${ }^{14}$ CLINEBELL, Howard J. Aconselhamento Pastoral. São Leopoldo: Sinodal, 1987. p. 25.

${ }^{15}$ Pseudônimo.

${ }^{16}$ BOWLBY, John. Apego. 3. ed. São Paulo: Martins Fontes, 2002. (Apego e Perda, v. 1); BOWLBY, John. Separação: Angústia e Raiva. São Paulo: Martins Fontes, 2004a. (Apego e Perda, v. 2). BOWLBY, John. Perda: Tristeza e Depressão. São Paulo: Martins Fontes, 2004b. (Apego e Perda, v. 3). 
mais forte e/ou mais sábia"17. Tal comportamento contribui para a sobrevivência do indivíduo na medida em que a figura de apego protege e cuida da pessoa apegada. A expressão figura de apego diz respeito à pessoa que assume um papel significativo na relação que se estabelece com aquela que recebe cuidado. Na infância, em geral esse papel é desempenhado pela mãe e pelo pai. No caso de crianças educadas por outros adultos, esses se tornam figuras de apego para a criança. Com o passar do tempo, o comportamento de apego leva ao desenvolvimento de laços afetivos ou apegos, sendo que os comportamentos de apego são ativos durante todo o ciclo vital. ${ }^{18}$

A cada experiência vivenciada com seus cuidadores, a criança procura compreender, mesmo que inconscientemente, como sua figura de apego reagirá à sua necessidade de proteção e conforto. Essa reação do cuidador às necessidades da criança fará com que ela desenvolva um apego seguro ou inseguro. ${ }^{19}$ Bowlby observou que o padrão de apego seguro é desenvolvido quando uma criança tem uma base segura a partir da qual ela pode explorar o ambiente ao seu redor e retornar quando se sente cansada ou com medo. ${ }^{20}$

Já o apego inseguro pode ser desmembrado em dois tipos: ansioso e evitante. No apego ansioso (ou ambivalente), a criança não está certa "se seus pais estarão disponíveis ou responsivos ou úteis quando chamados" ${ }^{\text {21 }}$. Com isso, seu sistema de apego é hiperativado, favorecendo um comportamento de luta e protesto para obter atenção, amor e apoio da figura de apego.

No apego evitante, a criança "não tem a confiança de que, quando ela procurar atendimento, será respondida de maneira útil; pelo contrário, ela espera ser recusada"22. Desse modo, seu sistema de apego é reprimido ou desativado, sendo que a criança reage à indisponibilidade da figura de apego mediante distanciamento emocional.

Alguns autores descrevem, ainda, um terceiro tipo de apego inseguro, chamado de ansioso-evitante (ou desorganizado), caracterizado por comportamentos conflitantes, desorientados ou temerosos. ${ }^{23}$ Quando seu sistema de apego é ativado, ela busca a proximidade da figura de apego ao mesmo tempo que teme essa proximidade. Esse padrão de apego é mais comum entre bebês maltratados. Traumas ou perdas não resolvidas dos cuidadores também podem contribuir para o apego desorganizado dos

${ }^{17}$ BOWLBY, John. The Making and Breaking of Affectional Bonds. London: Tavistock, 1979. p. 129. Originally published in Br. J. Psychiat, 130, p. 201-210, 421-431, 1977. p. 203.

${ }_{18}$ BOWLBY, 2004b, p. 38-41.

${ }^{19}$ ESPERANDIO, Mary Rute G.; AUGUST, Hartmut. Teoria do Apego e Comportamento Religioso. Interações - Cultura e Comunidade, Belo Horizonte, v. 9, n. 16, p. 248, jul./dez. 2014.

${ }^{20}$ BOWLBY, 1977, p. 206.

${ }^{21}$ BOWLBY, J. A Secure Base: Parent-Child Attachment and Healthy Human Development. Reprint edition. New York: Basic, 1988. p. 167.

${ }^{22}$ BOWLBY, 1988, p. 167.

${ }^{23}$ GRANQVIST, P. et al. Disorganized attachment in infancy: a review of the phenomenon and its implications for clinicians and policy-makers. Attachment and Human Development. 2017. Disponível em: $<\mathrm{https} / /$ doi.org/10.1080/14616734.2017.1354040>. 
filhos, na medida em que essas experiências podem levar os cuidadores a comportamentos sutilmente assustadores, assustados ou dissociativos em relação ao bebê. ${ }^{24}$

Esses diferentes modelos de apego são desenvolvidos ao longo da história dos relacionamentos com as figuras de apego e "são integrados à estrutura de personalidade na forma de modelos internos e gerais de funcionamento que determinarão as características do self frente às situações da vida" ${ }^{25}$. O estilo de apego tem impacto em vários aspectos da formação da subjetividade, na avaliação que cada um faz de si e dos outros, nas expectativas quanto ao parceiro ou parceira, na maneira como a sexualidade é encarada e praticada, na forma como ela se relaciona no ambiente profissional, como ela lida com conflitos etc. ${ }^{26}$

À medida que a criança se desenvolve física e emocionalmente, "seu comportamento de apego passa a ser menos frequente e menos intensamente ativado"27. A partir da adolescência, a pessoa desenvolve outras maneiras de suprir suas necessidades de porto seguro. Quando a proximidade física não for possível ou adequada, a sensação de porto seguro poderá ser obtida por outros caminhos, tais como "fotografias, mensagens virtuais e telefonemas" ${ }^{28}$.

Já na fase adulta, o parceiro, a parceira em uma relação amorosa assume um para o outro, papéis próprios de uma figura de apego. Em tais relações amorosas, a pessoa adulta com apego seguro tende a comportar-se de modo equilibrado, visto que ela se sente confortável, aliviada e afetivamente suprida no relacionamento. ${ }^{29}$ Uma pessoa com apego seguro é responsável, consistente, confiável, não fica tensa nem se fecha, apresenta maior satisfação no relacionamento, proporciona saúde emocional no relacionamento, é grande apaziguadora de conflitos, é mentalmente flexível, avessa a joguinhos, confortável com a proximidade e despreocupada com fronteiras, rápida em perdoar e confiante em melhorar o relacionamento. ${ }^{30}$

Pessoas de apego ansioso realizam tentativas excessivas de restabelecer contato, agem com hostilidade e vingança, ameaçam romper com a intenção de alcançar o objetivo pretendido, manipulam e fazem o outro ficar com ciúmes. ${ }^{31}$

Pessoas com estilo de apego evitante apresentam uma solidão arraigada, veem a intimidade como fraqueza, reprimem suas emoções, mantêm distância mental nos relacionamentos românticos e uma rota de escape, afastam-se mesmo quando as coisas estão indo bem e investem em relacionamentos impossíveis. Num acontecimento perturbador, como um divórcio ou uma doença, suas defesas caem e ela passa a se comportar como ansiosa. ${ }^{32}$

${ }^{24}$ GRANQVIST et al., 2017, p. 2, 3.

${ }^{25}$ ABREU, Cristiano Nabuco de. Teoria do Apego. São Paulo: Casa do Psicólogo, 2005. p. 15.

${ }^{26}$ MIKULINCER; SHAVER, 2010.

${ }^{27}$ ESPERANDIO; AUGUST, 2014, p. 246, 247.

${ }^{28}$ ESPERANDIO; AUGUST, 2014, p. 247.

${ }^{29}$ MIKULINCER; SHAVER, 2010, p. 21.

${ }^{30}$ LEVINE, Amir; HELLER, Rachel S. F. Apegados. Ribeirão Preto: Novo Conceito, 2013. p. 143-150.

${ }^{31}$ LEVINE; HELLER, 2013, p. 90-104.

32 LEVINE; HELLER, 2013, p. 121-139. 
O estudo pioneiro aproximando a ciência da religião com a psicologia cognitiva utilizando a perspectiva da Teoria do Apego foi publicado em 1990 por Kirkpatrick e Shaver ${ }^{33}$. Eles pesquisaram a correlação entre as experiências de apego na infância e as práticas religiosas na vida adulta. Posteriormente, Granqvist ampliou as pesquisas sobre a influência do apego da infância na religiosidade adulta. ${ }^{34}$ De acordo com Kirkpatrick, "Deus atua efetivamente como uma figura de apego para muitos fiéis" 35 , pois, "para muitas pessoas em muitas religiões, esse sistema de apego está fundamentalmente envolvido em seus pensamentos, crenças e raciocínios sobre Deus e seu relacionamento com Deus" ${ }^{\prime 36}$.

Pesquisas apontam uma forte correlação entre os estilos de apego, saúde mental e espiritualidade. ${ }^{37}$ Visto que a crença num Deus pessoal e amoroso com quem a pessoa experimenta um relacionamento próximo e seguro contribui para a saúde mental do indivíduo, o apego a Deus pode ser um meio importante para atenuar o sofrimento e reparar os modelos internos de funcionamento da pessoa após uma perda ou por causa de experiências de abandono por outras figuras de apego. ${ }^{38}$

Para que mudanças nos modelos internos de funcionamento ocorram de forma intencional, é necessário "conhecer a si mesmo e as pessoas à sua volta sob a perspectiva da Teoria do Apego"39. Desenvolve-se assim uma saudável desconfiança em relação aos modelos mentais praticados pelos pais e que certamente influenciaram seus próprios modelos. Nesse processo, os sentimentos criados pelas experiências negativas dos apegos anteriores são reconhecidos e reavaliados, permitindo a modificação do comportamento mediante a adoção de um estilo seguro de ser.

\section{Metodologia}

Este estudo de caso tem por base a análise de um processo de aconselhamento espiritual realizado com uma jovem. A pesquisa foi registrada na Comissão Nacional de Ética em Pesquisa - CONEP e aprovada no Comitê de Ética em Pesquisa da PUCPR. ${ }^{40}$

Um estudo de caso permite uma compreensão em profundidade de um caso em particular ${ }^{41}$ e aponta elementos que podem ser utilizados na compreensão de outros fenômenos semelhantes. Adotou-se a metodologia de estudo de caso individual instrumental. ${ }^{42}$ A partir desse estudo, pode-se avaliar a eficácia do aconselhamento como

\footnotetext{
33 KIRKPATRICK; SHAVER, 1990.

34 GRANQVIST, P. Religiousness and Perceived Childhood Attachment: On the Question of Compensation or Correspondence. Journal for the Scientific Study of Religion, v. 37, n. 2, p. 350-367, 1998. p. 343.

35 KIRKPATRICK, 2005, p. 55.

36 KIRKPATRICK, 2005, p. 56.

37 MIKULINCER; SHAVER, 2010.

38 AUGUST, Hartmut; ESPERANDIO, Mary R. G. Apego a Deus: revisão integrativa de literatura empírica. Horizonte, Belo Horizonte, v. 17, n. 53, p. 1.057, maio/ago. 2019.

39 LEVINE; HELLER, 2013, p. 49.

${ }^{40}$ Protocolo de aceite código 49743315.4.0000.0020, em 20/10/2015.

${ }^{41}$ CRESWELL, John W. Investigação Qualitativa \& Projeto de Pesquisa. 3. ed. Porto Alegre: Penso, 2014. p. 87.

42 CRESWELL, 2014, p. 87.
} 
caminho para a modificação dos modelos internos de funcionamento do sistema de apego e do apego a Deus.

Procedimentos para coleta de dados. Para a coleta dos dados foram adotados os procedimentos propostos por Creswell. ${ }^{43}$ Desde a primeira sessão, buscou-se estabelecer um vínculo seguro no relacionamento conselheiro-aconselhanda "e o sentimento de que se está trabalhando em conjunto em direção a objetivos comuns" ${ }^{\text {"44. No }}$ primeiro encontro, Fernanda preencheu a escala de apego interpessoal ECR-RS ${ }^{45}$ e o Inventário de Apego a Deus - IAD-Br. ${ }^{46}$

Todas as sessões foram gravadas em áudio, sendo seus conteúdos posteriormente transcritos. As anotações realizadas pelo conselheiro durante cada sessão também serviram de fonte de coleta de dados, assim como os apontamentos realizados após cada sessão, contendo avaliações e lembretes de assuntos a serem tratados nas próximas. A transcrição desses conteúdos resultou em 137 páginas de dados para análise.

Os encontros foram agendados na frequência demandada por Fernanda, sem prazo prévio para conclusão. Os encontros que compõem este estudo ocorreram, inicialmente, em intervalos semanais e depois em períodos mais espaçados. Foram realizados sete encontros, com duração média de 90 minutos. Para assegurar o bom andamento dos mesmos, procedeu-se o agendamento prévio do local, preparação do ambiente, manutenção do gravador, seleção e preparação do material a ser utilizado em cada encontro e garantia de privacidade.

$\mathrm{Na}$ última sessão, Fernanda preencheu novamente os instrumentos ECR-RS e IAD-Br. O objetivo era avaliar possíveis alterações nos índices de ansiedade e de evitação nos relacionamentos interpessoais e no relacionamento com Deus, em comparação ao primeiro encontro.

Para o propósito deste estudo, foram considerados os primeiros sete encontros ${ }^{47}$, embora ambos, conselheiro e aconselhanda, considerem que sessões adicionais possam ser úteis para que os objetivos almejados no aconselhamento sejam consolidados.

Procedimentos de análise dos dados. Visto que o propósito consiste em identificar "evidências da evolução" ${ }^{48}$ de Fernanda em seus vínculos de apego com Deus, consigo mesma e com as pessoas, será dada ênfase aos dados coletados no primeiro e no último encontro. A transcrição dos aconselhamentos foi analisada pelo método de codificação descritiva ${ }^{49}$, utilizando o software de análise qualitativa Atlas.ti®. Esse método consiste num processo cíclico de codificação e recodificação dos conteúdos ou códigos, compostos por segmentos de falas, até que eles estejam satisfatoriamente

${ }^{43}$ CRESWELL, 2014, p. 124.

${ }^{44}$ ALLEN, 2013, p. 171.

${ }^{45}$ MOREIRA, Helena et. al. Assessing Adult Attachment Across Different Contexts: Validation of the Portuguese Version of the Experiences in Close Relationships - Relationship Structures Questionnaire. Journal of Personality Assessment, 2014.

${ }^{46}$ AUGUST, Hartmut; ESPERANDIO, Mary Rute G.; ESCUDERO, Fabiana T. Brazilian Validation of the Attachment to God Inventory (IAD-Br). Religions, 9, 103, 21p., 2018.

${ }^{47}$ CRESWELL, 2014, p. 90.

${ }^{48}$ CRESWELL, 2014, p. 161.

49 CRESWELL, 2014, p. 154. 
depurados. Esses códigos foram associados a quatro categorias relacionadas ao referencial teórico da Teoria do Apego: a história de Fernanda com suas experiências anteriores de apego, o apego a Deus, a base interna e o apego na relação afetiva.

$\mathrm{Na}$ etapa seguinte, os códigos foram associados em redes semânticas, sendo analisados pelo método da interpretação direta, no qual o pesquisador se direciona para um único exemplo (neste caso, os aconselhamentos realizados com Fernanda), do qual extrai o significado encontrado. ${ }^{50}$

\section{Resultados e discussão}

A seguir, são apresentados os resultados da análise, bem como a discussão dos elementos extraídos dos encontros.

\section{A história de Fernanda}

A Teoria do Apego dá ênfase especial às experiências da pessoa com seus cuidadores na infância e às relações de apego anteriores como caminho para a compreensão das relações de apego atuais. ${ }^{51}$ Os relatos das experiências do passado de Fernanda foram utilizados na medida em que auxiliaram na compreensão dos estilos de apego atuais e na elaboração de novos modelos de funcionamento.

Histórico familiar. Fernanda cresceu numa família de classe média baixa, sendo caçula numa família composta por pai, mãe e quatro irmãos. Durante toda a infância, adolescência e juventude, ela vivencia uma estrutura familiar com problemas. Sua mãe foi percebida como extremamente autoritária, ao passo que o pai usava de violência física na relação com a mãe. Diante dos filhos, o pai é ausente, participando muito pouco da educação. Fernanda buscava continuamente a atenção do pai, embora sem sucesso. A aconselhanda não se lembra de nada que se orgulhe de dizer que foram ensinamentos dos pais. Sua vontade era obter a aprovação dos pais por meio dos estudos e da carreira profissional.

Histórico de relacionamentos românticos. Aos 15 anos, Fernanda se envolve com um rapaz de 18 anos. Por cinco anos moram juntos, numa convivência turbulenta, devido à característica violenta do namorado. Fernanda teve muita dificuldade em romper o relacionamento, pois tinha receio de que o rompimento levasse o rapaz ao suicídio, gerando-lhe um posterior sentimento de culpa. Em outros momentos, o namorado queria terminar e ela tinha medo de ser tomada de pensamentos suicidas, caso ele terminasse. Com o passar do tempo, Fernanda ficou bem depressiva. Quando finalmente cria coragem de romper a relação, vê-se grávida. Seu filho tem hoje oito anos de idade.

Um segundo envolvimento afetivo leva Fernanda a uma igreja evangélica. Porém os ciúmes que as moças da igreja tinham dela e a insegurança do rapaz em assumir o namoro perante a comunidade de fé resultam no fim do relacionamento. Com isso, Fernanda deixou de frequentar essa igreja. Um terceiro relacionamento amoroso

\footnotetext{
${ }^{50}$ CRESWELL, 2014, p. 161.

51 MIKULINCER; SHAVER, 2010, p. 121.
} 
leva-a a frequentar uma outra comunidade de fé, onde foi batizada. Nessa nova comunidade, Fernanda afirma "ter sentido a presença de Deus" e passa a compartilhar sua experiência religiosa com outras pessoas. Porém, com o fim desse namoro, também deixa de frequentar essa comunidade.

Fernanda entrou em vários relacionamentos instáveis ao longo dos últimos vinte anos. No momento, sente uma elevada insegurança em relação ao namoro atual. O roteiro familiar onde pai e mãe serviram de figuras de apego inadequadas acabou sendo, em grande parte, reproduzido por Fernanda em seus relacionamentos amorosos.

Histórico de fé. A mãe de Fernanda participa assiduamente das práticas religiosas da igreja católica. Durante sua infância, a aconselhanda a acompanhava nessas práticas, embora não visse sentido nisso. Quanto à fé do pai, Fernanda afirma que ele nunca foi praticante. Suas primeiras experiências de fé começam na juventude. A enchente que alagou sua casa e da qual conseguiu sair milagrosamente é recordada vividamente como um livramento proporcionado por Deus. Depois que começou a frequentar uma igreja evangélica, Fernanda sentiu a presença de Deus e passou a falar para as outras pessoas que devia a Deus tudo que havia conquistado.

\section{Aconselhamento espiritual como estratégia para ampliar o apego a Deus}

De acordo com a teologia cristã, "a pessoa pode ser incentivada a buscar a proximidade com Deus, nos mesmos moldes que uma pessoa apegada procura a proximidade com sua figura de apego" ${ }^{\text {2 }}$. Contudo, o histórico da infância da aconselhanda indica que ela percebe Deus como distante, como, aliás, também o era seu pai. Somente quando entra no mercado de trabalho, Deus passa a ser relevante em sua vida, embora só nos momentos de crise.

Para avaliar o estilo de apego a Deus, no primeiro encontro a aconselhanda responde ao Inventário de Apego a Deus (IAD-Br). Nesse instrumento, quanto mais baixos forem os escores de ansiedade e de evitação (numa escala de 1 a 7), mais seguro será o estilo de apego a Deus da pessoa. Por outro lado, quanto mais altos os escores da ansiedade e da evitação, mais ansioso ou evitante, respectivamente, será seu apego a Deus. ${ }^{53}$ As respostas da aconselhanda ao IAD-Br apresentaram um índice de evitação de 3,6 e um índice de ansiedade de 3,9. Esses dados apontam para um apego moderadamente ansioso com Deus.

Para os cristãos, um relacionamento de confiança e dependência de Deus (apego seguro a Deus) permite superar as angústias da vida. ${ }^{54}$ Por essa razão, o conselheiro propõe a busca da paz consigo mesma, com sua história e com Deus, dando ênfase ao desenvolvimento de um apego seguro com Deus.

\footnotetext{
${ }^{52}$ ESPERANDIO; AUGUST, 2014, p. 255.

${ }^{53}$ MIKULINCER; SHAVER, 2010, p. 28.

54 TILLICH, Paul. A Coragem de Ser. Rio de Janeiro: Paz e Terra, 1967. p. 130.
} 
Com o propósito de ampliar o apego seguro de Fernanda em Deus, o conselheiro explica que Deus é um ser relacional e de amor ${ }^{55}$ e que, como tal, criou pessoas para se relacionarem com ele. Deus está disponível tanto nas pequenas quanto nas grandes decisões da vida do ser humano. No relacionamento com Deus, cada pessoa pode reconhecer sua identidade e seu valor, ampliando assim a segurança na base interna.

Para estimular a aconselhanda a restabelecer um relacionamento continuado com Deus, ela recebe o livro "O Bom e Maravilhoso Deus" ${ }^{56}$, cujo conteúdo pretende auxiliar as pessoas a construírem uma imagem positiva de Deus, favorecendo sua jornada de formação espiritual. Ao longo dos encontros, a aconselhanda reporta que está lendo e gostando do livro. Ela também está fortalecendo seu apego com Deus por meio da meditação e leitura da Bíblia. Para que ela e seu namorado possam ser alimentados espiritualmente juntos e possam desenvolver relacionamentos saudáveis (inclusive apegos seguros) com outras pessoas, ela é estimulada a buscar uma comunidade de fé de sua escolha. A participação num evento para casais permite que eles reavaliem seu relacionamento.

Ao término dos aconselhamentos, Fernanda preenche novamente o Inventário de Apego a Deus. Em comparação com os dados coletados no primeiro encontro, a evitação foi reduzida de 3,6 para 2,6, ao passo que a ansiedade baixou de 3,9 para 2,7. Esses dados indicam que o apego a Deus de Fernanda está mais seguro.

Ao contrário dos primeiros encontros, quando as falas da aconselhanda associadas a Deus eram somente expressões de angústia ("meu Deus", "ai meu Deus", "meu Deus do céu"), no último encontro as falas apontam para um apego a Deus mais seguro:

Falo, "meu Deus, tira esses pensamentos da minha cabeça". [...] Sempre antes de dormir eu agradeço, tenho uma conversa (com Deus). Quando meu emocional está muito à flor da pele, eu falo dos problemas para Ele. [...] Nos momentos de pura aflição eu procuro Deus. [...] A gente está se apegando bastante em Deus.

Ao longo dos encontros, ambos passaram a buscar mais a Deus como fonte de direção para suas decisões, algo muito diferente do que ela havia vivenciado no relacionamento entre seus pais e em seus namoros anteriores.

\section{Aconselhamento espiritual como estratégia para ampliar a base interna}

Outro propósito do aconselhamento foi tornar a base interna da aconselhanda mais segura, se reconhecendo no que é única, seus sonhos e oportunidades e como pode reorientar sua vida em busca da vida plena. A construção de uma base interna

\footnotetext{
55 SOUZA, 2002, p. 59.

56 SMITH, James Bryan. O Maravilhoso e Bom Deus. São Paulo: Vida, 2010.
} 
segura é facilitada por meio de um relacionamento seguro com Deus ${ }^{57}$, que sabe o potencial de cada um e pode guiá-lo continuamente a essa melhor versão de si. $^{58}$

No período inicial de aconselhamento, as falas da aconselhanda associadas à base interna exprimiam sua insegurança:

Nunca pensei em família feliz, em filho. [...] Não sei se foi o meu dedo podre para que isso aconteça. [...] Minha vontade de estar com ele é imensa, é grande, é enorme. [...] Fico meio perdida e até às vezes com medo de falar alguma coisa que ele entenda que estou dando "piti" por ciúmes, sabe? [...] A ex-mulher ter começado a namorar me abalou também.

Pessoas de estilo ansioso, "por não terem consciência do sistema de apego, se arriscam a sofrer muito em relacionamentos" 59 . E o "dedo podre" citado por Fernanda se refere à sua suspeita de que ela não está sabendo escolher seus namorados, visto que todas as suas experiências amorosas foram marcadas por relacionamentos turbulentos.

Uma pessoa de estilo ansioso "possui uma capacidade singular de perceber quando o seu relacionamento está ameaçado" ${ }^{60}$. Assim, cada vez que o namorado se comunica com sua ex-mulher para tratar da educação dos filhos deles, Fernanda fica muito insegura. Como o namorado acabou tendo um relacionamento fugaz com a ex-mulher após uma briga com a aconselhanda, muitas das brigas do casal surgem porque o namorado afirma que Fernanda está duvidando do seu arrependimento.

Com relação à insegurança nas situações onde o parceiro se comunica com sua ex-mulher para tratar dos filhos, o conselheiro argumenta que essa comunicação faz parte das responsabilidades dos pais, independente se estão casados ou não. ${ }^{61} \mathrm{~A}$ aconselhanda compreendeu que os sentimentos são alimentados pelas experiências passadas e que é mais seguro tomar decisões com base em evidências do presente e não nos sentimentos. ${ }^{62}$

Um dos desafios para pessoas de estilo ansioso consiste em reconhecer e aceitar suas verdadeiras necessidades num relacionamento. ${ }^{63}$ Ao refletir sobre os gatilhos que levam a suas explosões de crítica, Fernanda se dá conta de que são as menções à ex-mulher do namorado que a deixam insegura. A adoção de novos hábitos possibilita que ela lide saudavelmente com essas situações. ${ }^{64}$

Ao final dos aconselhamentos, os episódios de estresse cessaram completamente, pois Fernanda desenvolveu uma base segura interna de modo que as situações onde o namorado se comunica com a ex-mulher já não a afetam mais:

\footnotetext{
57 ALLEN, 2013, p. 234.

58 ORTBERG, John. ICH - einzigartich: Wie ich so werde, wie Gott wollte, dass ich bin. München: Random House, 2010. p. 13.

${ }^{59}$ LEVINE; HELLER, 2013, p. 89.

${ }^{60}$ LEVINE; HELLER, 2013, p. 91.

61 AUGUST, Hartmut. Potencial Invisível na Igreja. Curitiba: Esperança, 2014. p. 75.

${ }^{62}$ LEVINE; HELLER, 2013, p. 92.

${ }^{63}$ LEVINE; HELLER, 2013, p. 111.

${ }^{64}$ DUHIGG, Charles. O Poder do Hábito. Rio de Janeiro: Objetiva, 2012.
} 
Com relação à ex-mulher dele, ela já não me incomoda mais. Acho que a segurança com relação a ela mudou muito mesmo, positivamente. [...] Minha insegurança com relação à ex-mulher dele já se esvaiu.

As estratégias do namorado de agir com hostilidade e ameaçar com ruptura quando algo não sai de seu jeito são características de um estilo de apego ansioso. ${ }^{65}$ Contudo, com o passar do tempo, essas estratégias não funcionam mais:

Quanto mais eu mostrava para ele que eu estava assim diferente das reações que eu sempre tenho de desespero, choro e grito, ele ficou assim sem saber o que fazer. Ele queria me agradar de qualquer jeito e se ajoelhou assim, sabe.

Embora ainda reconheça uma certa insegurança em si, a aconselhanda está ampliando significativamente sua base segura interna:

Eu ainda preciso ser mais autoconfiante. [...] Essas coisinhas pequenas estão mudando aos poucos. Está sendo um tijolinho de cada vez. [...] Eu tenho que mudar para mim, porque se amanhã ou depois não acontecer, eu não ficar com o namorado, eu preciso estar bem.

Considerando que uma base interna segura favorece a satisfação nos apegos interpessoais ${ }^{66}$, o conselheiro argumenta sobre a importância de Fernanda estar bem consigo mesma para poder desfrutar mais o relacionamento amoroso.

\section{Aconselhamento espiritual como estratégia para ampliar a segurança no apego na relação afetiva}

Os motivos que trouxeram Fernanda ao aconselhamento eram sua insegurança no namoro e as constantes brigas do casal. Visto que a capacidade de prosperar é poderosamente afetada pelo parceiro romântico ou parceira romântica ${ }^{67}$, um dos propósitos do aconselhamento consistia em contribuir para que a aconselhanda desenvolvesse um apego seguro na relação amorosa. Essa tarefa é facilitada na medida em que a pessoa desenvolve um relacionamento com Deus (apego seguro com Deus) e uma autoestima saudável (base interna segura). ${ }^{68}$

No primeiro encontro, Fernanda preencheu o instrumento ECR-RS para mensurar seu apego interpessoal. Quanto mais baixos forem os escores de ansiedade e de evitação (numa escala de 1 a 7), mais seguro será o estilo de apego da pessoa. Por outro lado, quanto mais altos os escores da ansiedade e da evitação, mais ansioso ou

${ }^{65}$ LEVINE; HELLER, 2013, p. 99.

${ }^{66}$ MIKULINCER; SHAVER, 2010, p. 177.

${ }^{67}$ LEVINE; HELLER, 2013, p. 43.

${ }^{68}$ ALLEN, 2013, p. 238. 
evitante, respectivamente, será seu estilo de apego. ${ }^{69} \mathrm{O}$ preenchimento do ECR-RS indicou que Fernanda apresentava um índice de evitação de 2,8 e um índice de ansiedade de 7, valor máximo possível. Esses dados evidenciam muita ansiedade no relacionamento, confirmando o motivo que a fizeram buscar ajuda. No início do aconselhamento, predominam os relatos que expressam a ansiedade da aconselhanda na relação com o parceiro:

Desenvolvi, na verdade, uma insegurança muito forte do namorado me deixar. [...] Sinceramente não sei o que é, se é implicância minha ou se é ciúmes. Não sei se ele quer cuidar da ex-mulher ou se é por ser refém dela em prol dos filhos. [...] Por dentro fico me remoendo, porque não era aquilo que eu queria.

A ansiedade de Fernanda resulta em comportamento ansioso também na educação de seu filho, de modo que ela agora, como mãe, está reproduzindo, inconscientemente, o modelo de apego vivenciado na infância. ${ }^{70}$ Refletindo sobre como sua mãe era rígida e oferecia-lhe um amor condicional quando criança, Fernanda percebe-se fazendo o mesmo.

A aconselhanda foi estimulada "a revisar e atualizar suas crenças de maneira a se ajustar melhor às experiências de relacionamento atuais e aos parceiros atuais"71. Os encontros ajudaram-na a refletir sobre sua história e compreender como os apegos inseguros na infância, marcados por um pai evitante e uma mãe ansiosa, moldaram seus modelos internos de funcionamento, desenvolvendo nela um estilo de apego altamente ansioso.

Como Fernanda e seu parceiro têm dificuldade para se expressarem de maneira saudável, ela recebeu a tarefa de praticar com ele uma comunicação segura, substituindo as críticas por palavras de afirmação. ${ }^{72}$ Ao término dos aconselhamentos, Fernanda ainda apresenta comportamentos de estilo ansioso:

A gente continua se desentendendo bastante. [...] Para mim é uma batalha constante ter essa plenitude, de confiança e de não sentir mais angústias. [...] Parece que eu estou numa camisa de forças. Eu queria estar mais leve com relação a esses sentimentos.

Contudo, ao rever suas atitudes e crenças e agir de modo mais seguro, Fernanda está caminhando em direção a uma segurança crescente no apego com o namorado ${ }^{73}$ :

Vejo que estou dando mais chance para ele expor as situações. Estou perguntando ao invés de acusar, quando tenho alguma dúvida. [...] Aos pouquinhos acho que a gente vai se acertar. [...] Quando eu comecei a vir aqui, se eu fosse pensar, eu tinha que ter tomado uma atitude de parar o relacionamento.

${ }^{69}$ MIKULINCER; SHAVER, 2010, p. 28.

${ }^{70}$ MIKULINCER; SHAVER, 2010, p. 121.

${ }^{71}$ MIKULINCER; SHAVER, 2010, p. 508.

72 CHAPMAN, Gary. As Cinco Linguagens do Amor para Solteiros. São Paulo: Mundo Cristão, 2005.

${ }^{73}$ LEVINE; HELLER, 2013, p. 101. 
Ambos desenvolveram novas maneiras de se comunicar e as necessidades agora são expressas de modo mais claro. ${ }^{74}$ As discussões causadas por ciúmes infundados se tornaram menos frequentes. A apropriação de um apego seguro também fica evidenciado nas mudanças de comportamento do namorado:

Meu namorado teve bastante evolução de comportamento. [...] Essa mudança dele de comportamento vai fazendo com que eu vá percebendo também as minhas atitudes.

Visto que um comportamento seguro contribui para ela tornar-se segura ${ }^{75}$, Fernanda é incentivada a não desconfiar sem evidências concretas. Ela e o namorado estão lendo o livro "O Significado do Casamento"76, o que tem ajudado na compreensão do casamento na perspectiva cristã.

Ao término dos aconselhamentos, Fernanda preencheu novamente o instrumento ECR-RS e o resultado indicou que seu estilo de apego interpessoal se tornou mais seguro. A evitação baixou de 2,8 para 1 (nível mínimo) e a ansiedade baixou de 7 (nível máximo) para 4,7.

\section{Estágios em direção à segurança nos apegos}

Quando Fernanda veio buscar ajuda, ela estava no estágio da alienação, adotando comportamentos automáticos, sem se dar conta de como seus modelos internos de funcionamento foram construídos. ${ }^{77}$ Ela não fazia ideia de como as experiências negativas com seus pais a haviam moldado.

À medida que a aconselhanda foi compreendendo sua história na perspectiva da Teoria do Apego, ela foi passando ao estágio do autoconhecimento. ${ }^{78}$ As experiências da infância e seus relacionamentos românticos foram utilizados como material de reflexão, permitindo-lhe compreender como seu apego ansioso havia sido moldado e como as emoções ativadas pelas experiências anteriores a estavam levando a manter e reforçar comportamentos ansiosos.

Ao adotar comportamentos mais seguros, Fernanda passou do estágio do autoconhecimento para o estágio da apropriação. A caminhada em direção à segurança nos apegos $^{79}$ de Fernanda não foi linear, mas marcada por avanços, retrocessos e novos avanços. Ela compreendeu que os modelos internos de funcionamento são modificados a partir de novas ações. ${ }^{80}$ Para isso, as leituras e tarefas praticadas por ela foram muito importantes.

\footnotetext{
74 LEVINE; HELLER, 2013, p. 113.

75 ALLEN, 2013, p. 211.

${ }^{76}$ KELLER, Timothy. O Significado do Casamento. São Paulo: Vida Nova, 2012.

77 LEVINE; HELLER, 2013, p. 21.

78 LEVINE; HELLER, 2013, p. 49.

${ }^{79}$ LEVINE; HELLER, 2013, p. 200.

${ }^{80}$ ALLEN, 2013, p. 211.
} 


\section{O conselheiro ou a conselheira como figura reparadora de apego}

Em um relacionamento terapêutico seguro, o conselheiro ou a conselheira assume a função de figura reparadora de apego, na medida em que proporciona ao aconselhando ou aconselhanda um cuidado caracterizado pela constância, sensibilidade e receptividade das demandas da pessoa em busca de auxílio. ${ }^{81}$ Esse vínculo seguro compreende "uma relação de confiança e o sentimento de que se está trabalhando em conjunto em direção a objetivos comuns" "82. Neste sentido, cabe ao conselheiro ou à conselheira "desenvolver expectativas sólidas, paciente a paciente"

Noprimeiro encontro foi empregado o instrumento "FoconoAconselhamento", que consiste num roteiro no qual o aconselhando ou a aconselhanda e o conselheiro ou a conselheira concordam a respeito do foco central do aconselhamento. A aconselhanda pediu ajuda diante dos problemas no namoro. Ela desacreditava dos sentimentos, das vontades e redenções do atual namorado. Além disso, ela não estava sabendo lidar com o relacionamento do namorado com sua ex-mulher. Seu desejo era conseguir dar mais chance ao namorado e focar em coisas que realmente importam para ser feliz, sendo que pensar no seu filho era fonte de esperança.

Visto que "o relacionamento terapêutico é uma avenida principal de cura" 85 , Fernanda teve no conselheiro uma figura de apego provisória. Proveu-se, assim, um contexto favorável para processar as memórias do passado e reavaliar os modelos internos de funcionamento. ${ }^{86}$ Ela também sentiu confiança nas orientações, leituras e tarefas sugeridas pelo conselheiro, permitindo assim experimentar progressos visíveis em direção a uma maior segurança nos apegos.

Ao término dos aconselhamentos, Fernanda expressou gratidão pela ajuda recebida e reconheceu que é muito mais fácil caminhar acompanhada. Ela assim expressa: "O aconselhamento ajudou bastante, bastante mesmo". O relacionamento conselheiro-aconselhanda atuou como "função reparadora" ${ }^{87}$ de seus modelos internos de funcionamento.

\section{Considerações finais}

Este estudo de caso se propôs avaliar a aplicação e eficácia dos conceitos de apego e do apego a Deus num contexto de aconselhamento espiritual. Os encontros individuais proporcionaram um ambiente seguro, onde as experiências e emoções do passado puderam ser trabalhadas numa aliança conselheiro-aconselhanda, favorecendo a compreensão e modificação dos modelos internos de funcionamento.

\footnotetext{
${ }^{81}$ ABREU, 2005, p. 168.

82 ALLEN, 2013, p. 171.

${ }^{83}$ ALLEN, 2013, p. 248.

84 ALLEN, 2013, p. 196, 197.

${ }^{85}$ ALLEN, 2013, p. 167.

${ }^{86}$ ALLEN, 2013, p. 152.

${ }^{87}$ CLINEBELL, 1987, p. 25.
} 
Ao refletir sobre sua história, Fernanda compreendeu como suas experiências de apego inseguro na infância, marcadas por um pai evitante e uma mãe ansiosa, desenvolveram nela um estilo de apego altamente ansioso. Ela compreendeu também como seu apego ansioso levou-a a se envolver em relacionamentos românticos problemáticos, marcados pela ansiedade na relação.

Visto que "o amor próprio nasce de ser amado" $" 88$, o desenvolvimento de um apego seguro a Deus e de uma base interna segura contribuíram para que a aconselhanda pudesse se relacionar de forma segura com o namorado.

A aplicação dos instrumentos ECR-RS e IAD-Br foi muito útil para visualizar os modelos internos de funcionamento da aconselhanda. Trabalhar os itens do IAD-Br permitiu que Fernanda refletisse em que situações e por quais motivos ela se comportava da maneira como havia respondido no questionário. A ansiedade de Fernanda foi reduzida, permitindo que ela experimentasse um relacionamento mais próximo com Deus, maior confiança em si e maior segurança no relacionamento amoroso.

Futuros estudos sobre a utilização desse referencial teórico no tratamento de outros problemas, como por exemplo, no luto, contribuirão para ampliar e difundir a relevância de sua aplicação no cuidado de pessoas que sofrem.

\section{Referências}

ABREU, Cristiano Nabuco de. Teoria do Apego. São Paulo: Casa do Psicólogo, 2005.

ALLEN, Jon G. Restoring Mentalizing in Attachment Relationships. Arlington, USA: American Psychiatric, 2013.

AUGUST, Hartmut. Potencial Invisivel na Igreja. Curitiba: Esperança, 2014.

; ESPERANDIO, Mary R. G.; ESCUDERO, Fabiana T. Brazilian Validation of the Attachment to God Inventory (IAD-Br). Religions, 9, 103, 21 p., 2018

; ESPERANDIO, Mary R. G. Apego a Deus: revisão integrativa de literatura empírica. Horizonte, Belo Horizonte, v. 17, n. 53, p. 1.057, maio/ago. 2019.

; ESPERANDIO, Mary R. G. Teoria do Apego: Origem, Desenvolvimento e Perspectivas. Anais do Congresso ANPTECRE, v. 05, 2015b, p. ST1111.

BÍBLIA A Mensagem: Bíblia em Linguagem Contemporânea. São Paulo: Vida, 2011.

BOWLBY, John. Apego. 3. ed. São Paulo: Martins Fontes, 2002. (Apego e Perda, v. 1). . Separação: Angústia e Raiva. São Paulo: Martins Fontes, 2004a. (Apego e Perda, v. 2). Perda: Tristeza e Depressão. São Paulo: Martins Fontes, 2004b. (Apego e Perda, v. 3). A Secure Base: Parent-Child Attachment and Healthy Human Development. Reprint edition. New York: Basic, 1988.

. The Making and Breaking of Affectional Bonds. London: Tavistock, 1979. Originally

published in Br. J. Psychiat, 130, p. 201-10, 421-431, 1977.

CHAPMAN, Gary. As Cinco Linguagens do Amor para Solteiros. São Paulo: Mundo Cristão, 2005. CLINEBELL, Howard J. Aconselhamento Pastoral. São Leopoldo: Sinodal, 1987.

CRESWELL, John W. Investigação Qualitativa \& Projeto de Pesquisa. 3. ed. Porto Alegre: Penso, 2014.

DUHIGG, Charles. O Poder do Hábito. Rio de Janeiro: Objetiva, 2012.

${ }^{88}$ ALLEN, 2013, p. 171.

Estudos Teológicos | São Leopoldo | v. 60 | n. 1 | p. 298-314 | jan./jun. 2020 
ESPERANDIO, Mary Rute G.; AUGUST, Hartmut. Teoria do Apego e Comportamento Religioso. Interações - Cultura e Comunidade, Belo Horizonte, Brasil, v. 9, n. 16, p. 243-265, Jul./Dez. 2014. GRANQVIST, Pehr. Religiousness and Perceived Childhood Attachment: On the Question of Compensation or Correspondence. Journal for the Scientific Study of Religion, v. 37, Issue 2, p. 350-368, June 98.

; KIRKPATRICK, Lee A. Attachment and Religious Representations and Behavior. In: Handbook of Attachment: Theory, Research, and Clinical Applications. 2. ed. New York: Guilford, 2008. p. 906-933.

; MIKULINCER, Mario; SHAVER, Phillip R. Religion as attachment: normative processes and individual differences. Pers Soc Psychol Rev., 14(1), p. 49-59, Feb. 2010. Review.

; SROUFE, L. et al. Disorganized attachment in infancy: a review of the phenomenon and its implications for clinicians and policy-makers. Attachment and Human Development. Disponível em: <https://doi.org/10.1080/14616734.2017.1354040>.

KELLER, Timothy. O Significado do Casamento. São Paulo: Vida Nova, 2012.

KIRKPATRICK, Lee A. Attachment, Evolution, and the Psychology of Religion. New York: Guilford, 2005.

; SHAVER, Phillip R. An attachment-theoretical approach of romantic love and religious belief. Personality and Social Psychology Bulletin, v. 18, p. 266-275, 1992.

; SHAVER, Phillip R. Attachment Theory and Religion. Childhood Attachments, Religious Beliefs and Conversion. Journal for the Scientific Study of Religion, v. 29, n. 3, p. 315-334, Set. 1990.

LEVINE, Amir; HELLER, Rachel S. F. Apegados. Ribeirão Preto: Novo Conceito, 2013.

MIKULINCER, Mario; SHAVER, Philip R. Attachment in Adulthood - Structure, Dynamics, and Change. New York: Guilford, 2010.

MINER, Maureen. Back to the basics in attachment to God: revisiting theory in light of theology. Journal of Psychology and Theology, Cengage Learning, Inc., v. 35(2), p. 112-123, Summer 2007. MOREIRA, Helena et al. Assessing Adult Attachment Across Different Contexts: Validation of the Portuguese Version of the Experiences in Close Relationships - Relationship Structures Questionnaire. Journal of Personality Assessment, 2014.

ORTBERG, John. ICH - einzigartich: Wie ich so werde, wie Gott wollte, dass ich bin. München: Random House, 2010.

SMITH, James Bryan. O Maravilhoso e Bom Deus. São Paulo: Vida, 2010.

SOUZA, Ricardo Barbosa de. O Caminho do Coração. 4. ed. Curitiba: Encontro, 2002.

TILLICH, Paul. A Coragem de Ser. Rio de Janeiro: Paz e Terra, 1967. . Teologia Sistemática. São Leopoldo: Sinodal; EST, 2005. 